\title{
Sociocultural competence of 7-11 years old students from ethnic communities in the digital world
}

\begin{abstract}
The article presents a training model aimed at the formation of sociocultural competence in 7-11 years old students from ethnic communities in Bulgaria, based on Geert Hofstede's (2003) theory of culture. A schematical description of the teaching methodology of the model is offered as well as some results of a study among the trained students conducted according to pre-defined criteria and indicators. The article comprises methodological ideas for the formation of sociocultural competence in 7-11-year-old students in the conditions of digitalization considering the possibilities of the electronic textbooks, which are part of the compulsory educational content. It turns out that these textbooks are necessary for the purposes of training in the digital world, as well as for the COVID-19 pandemic.
\end{abstract}

Keywords: sociocultural competence, ethnic communities in Bulgaria, students, digital textbooks

\section{Introduction}

The Bulgarian society is a multicultural one. This implies a permanent contact between the representatives of different minority communities, which is characterized by tolerance, empathy and intercultural consideration.

The conditions of the digital world, as well as those caused by the Covid-19 pandemic, suggest some changes and limitations in social relations. They determine that people communicate through technology. In any case, these circumstances cannot displace the main issue related to the need of building skills for communication with representatives of different ethnic and cultural communities. On the contrary - it is the new technologies that provide more and more opportunities for communication and meeting with Others - by joining social networks, dating sites, job searching websites, chats, online trainings, etc. 
The dynamics of social and digital conditions along with the increased capabilities of the modern information society suggest more frequent communication between representatives of different ethnic and cultural communities. This is why there is an increased necessity to build sociocultural competence as a component of the communicative competence starting from an early school age. This issue is especially important for the progress of Bulgarian society, as the nature and specifics of the ethnic communities are projected onto communication and relationships within the school environment. Researchers are adamant that: "insofar as those differences are inherent in society, they are present at school” (Chavdarova-Kostova, 2010, p. 5)

The goal of the current study is to present a practically tested training model for forming sociocultural competence in 7-11 years old students belonging to different ethnic communities in Bulgaria, which is based on Geert Hofstede's (2003) theory of culture, as well as to indicate some methodological ideas for the formation of this competence in digital environment through the possibilities provided by the electronic textbooks.

Objectives:

1. To define and derive the main characteristics of the concept of "sociocultural competence" for the educational purposes according to the proposed model.

2. To reveal in the most general plan the training methodology and to present results obtained during the model approbation.

3. To present methodological ideas for the sociocultural competence formation in 7-11 years old students in the context of digitalization and the application of e-textbooks for this purpose.

4. To outline some productive solutions e-textbooks usage during the Covid-19 pandemic.

\section{The general theoretical context}

In the specialized scientific literature, the sociocultural competence is considered an essential component of the communicative competence. Researchers, in accordance with their goals, emphasize different characteristics of the concept while determining its content and thus outlining its parameters. What all authors agree on is the significance of that notion. It is believed that it serves to overcome the difficulties in the process of communication between representatives of different cultural backgrounds. 
The concept of "communicative competence" was first introduced by D. Hymes in the 1960s. He tried to develop further N. Chomsky's ideas about language competence. According to Chomsky, language competence comes down to acquiring knowledge of grammar rules. And one of Hymes' main ideas is to link language to culture. According to him, language and culture are related to the overall organization of speech. Therefore, in addition to grammatical correctness, feasibility, and acceptability, the author draws attention to sociocultural knowledge, which are all closely related to values, relations and motivation in communication. This knowledge is important, especially when learners develop initial purpose-oriented communication skills. As Hymes himself points out, the learning child must acquire competence: "when to speak, when not, and as to what to talk about with whom, when, where and in what manner" (Hymes, 1972, p. 277).

Hymes' model is gradually becoming the subject of numerous studies for the purposes of language teaching. In 1985, Jan van Eck developed another, broader model of communicative competence that combined almost all studies. It consists of six main components. The individual components (linguistic, discourse-strategic, socio-linguistic, sociocultural and social competences) provide clarity about the abilities that build communicative skills. The Linguistic competence is associated with mastery of grammatical structures and language rules. The Discourse competence finds expression in the ability of the learner to formulate and correctly use completed sentences, both in oral and written discourses. The Strategic competence is mostly associated with the use of verbal and nonverbal strategies by the participant in the communication act in case of special difficulties because of the lack of knowledge of certain words. The Sociolinguistic one is related to the ability to take into account the appropriateness of an expressions in accordance with the topic, the interlocutor, the situation, etc. during the act of communication. The Sociocultural competence is connected to the knowledge of the national-cultural specificities of the language studied as a foreign one. The Social competence is associated with the participants' abilities to engage in communication for professional or personal purposes (Ilieva-Baltova, 2004, pp. 101-102; Dimitrova, 2019, p.18).

This brief specialized review makes it clear that researchers define sociocultural competence as an integral part of the structure of the communicative competence itself. Its main components include knowledge of language, values, culture.

In the construct of "sociocultural competence", "culture" plays a key role in determining its characteristics. In the Bulgarian dictionary, the word "cul- 
ture" has many meanings. Two of them are: "1). A set of spiritual and material values created by humanity during its historical past. Spiritual culture. Material culture. Ancient culture. 2). Education, knowledge, upbringing. High culture. Low culture. I have a rich culture (Bulgarian online dictionary). One of the world-famous researchers of culture, Geert Hofstede, explains its essence as a set of four main elements: symbols, heroes, rituals and values. He defines values as the "core" of culture. According to Hofstede: "the world of the child in every culture is filled with symbols, characters and rituals that together they embody and recreate that culture. Behind these manifestations are the values of this culture. They are learned from birth and manifest in similar ways in different contexts: family, school, etc." (Hofstede, 2003, pp. 51-52).

For the purposes of this study, "competence" will be understood as knowledge, skills, and relations that students acquire during the education process. In the Bulgarian educational system, they are measured in accordance with the State Educational Standards, which are compliant with the European Framework of Key Competences for Lifelong Learning. These key competencies are fundamental for the Preschool and School Education Act (PSEA) and are described in Art. 77, para (1). of the Act, as follows: "1. Bulgarian language competences; 2 . skills to communicate in foreign languages; 3. mathematical competence and basic competences in natural sciences and technologies; 4 . digital competence; 5 . learning skills; 6 . social and civic competences; 7. initiative and enterprising; 8 . cultural competence and creative expression skills; 9. skills to support sustainable development, healthy lifestyles, and sports." (Zakon, 2016, p. 23).

The proposed educational model aims at forming sociocultural competence in 7-11 years old students belonging to different ethnic communities in Bulgaria. The model is based on the understanding that the development of sociocultural competence in students from the earliest school age will contribute to the mastery of knowledge, skills and relations, which ensure smooth communication with representatives of different cultures and ethnic communities. It is assumed that in order to make 7-11 years old students understand the culture of an ethnic community, it is necessary for them to know how the given culture manifests itself in symbols, heroes, rituals and values, as grounded in Hofstede's theory.

For the purposes of the model, these manifestations are pointed out as general sociocultural knowledge, obtained by receiving sociocultural information about symbols, heroes, rituals and values of the major ethnic communities in Bulgaria (Bulgarian, Romani, Turkish, Jewish, Armenian, etc.). 
In addition to Hofstede's concept, sociocultural knowledge is presented as a key component in the Common European Framework of Reference for Languages (2001), which lists elements and characteristics of a society's culture as follows:

1. Everyday living, e.g.:

- food and drink, meal times, table manners;

- public holidays;

- working hours and practices;

- leisure activities (hobbies, sports, reading habits, media)

2. Living conditions, e.g.:

- living standards (with regional, class and ethnic variations);

- housing conditions;

- welfare arrangements.

3. Interpersonal relations (including relations of power and solidarity) e.g. with respect to:

- class structure of society and relations between classes;

- relations between sexes (gender, intimacy);

- family structures and relations;

- relations between generations;

- relations in work situations;

- relations between public and police, officials, etc.;

- race and community relations;

- relations among political and religious groupings.

4. Values, beliefs and attitudes in relation to such factors as:

- social class;

- occupational groups (academic, management, public service, skilled and manual workforces);

- wealth (income and inherited);

- regional cultures;

- security;

- institutions;

- tradition and social change;

- history, especially iconic historical personages and events;

- minorities (ethnic, religious);

- national identity;

- foreign countries, states, peoples;

- politics;

- $\operatorname{arts}$ (music, visual arts, literature, drama, popular music and song); 
- religion;

- humour.

5. Body language. Knowledge of the conventions governing such behaviour form part of the user/learner's sociocultural competence.

6. Social conventions, e.g. with regard to giving and receiving hospitality, such as:

- punctuality;

- presents;

- dress;

- refreshments, drinks, meals;

- behavioural and conversational conventions and taboos;

- length of stay;

- leave-taking.

7. Ritual behaviour in such areas as:

- religious observances and rites;

- birth, marriage, death;

- audience and spectator behaviour at public performances and ceremonies;

- celebrations, festivals, dances, discos, etc. (CEFR, 2001, c. 102-103).

In this sense, it can be stated that the proposed model corresponds to the sociocultural knowledge specified in the Framework.

\section{A model for formation of sociocultural competence in 7-11-year-old students from different ethnic communities}

The proposed model of education is differentiated in various organizational forms: school extracurricular forms, forms of all-day education - activities by interest common for the elementary stage, clubs, etc. In its core, the model is an organization of the educational process having the main goal to form knowledge and skills in the 7-11 years old students to get to know the ethnic communities in Bulgaria (Bulgarians, Romani, Turkish, Jews, Armenians, etc.) through studying elements of their culture such as symbols, heroes, rituals, values. The main means of work is a special textbook, which includes selected tales that are typical for each ethnic community in Bulgaria, but one can find other cultures around the world represented as well. By genre and thematic diversity, the fairy tales are: folk, magical, legends, etc. In the textbook some colour applications are included, designed for visual activities 
for the students (for example, colouring elements of the community's culture: flag, traditional clothing) as well as activities related to cutting, application, etc.

In summary, the methodological work is based on the following stages:

1. Explicit presentation of sociocultural information about the ethnic communities in Bulgaria, which includes acquaintance with the symbols and rituals from the ritual-festive system of the community, significant historical facts, information about legendary heroes, etc.

2. Getting acquainted and comprehending the fairy tale, which reveals opportunities for awareness and interpretation of actions, deeds and relationships between the typical heroes. Through interpretation and evaluation performed by the students, they could reach an understanding of moral criteria established in the community.

3. Comparative analysis of two or more tales - Romani, Bulgarian, Armenian. The main purpose is to build students' ability to discover wisdom, virtues and generally accepted values.

4. Implementation of applied activities, related to establishing interdisciplinary links.

The conceptual framework of the methodological work is based on the understanding that before reading/listening to and analyzing a fairy tale or other literary work related to the culture of an ethnic community, it is an important condition for young students to have familiarized with the necessary sociocultural information about this community. This condition requires from the teacher a very good preliminary planning of the process of sociocultural competence formation in order to achieve consistency and completeness of each of the stages.

The observance of this sequence is justified by the understanding that thus a systematization of the sociocultural information is achieved, which at a later stage is transformed into a permanent sociocultural knowledge. The sociocultural information within the model is presented mostly by multimedia using PowerPoint, but in terms of digitalization, this can be achieved through various educational software products. During the model practical probation in real school environment, PhotoStory 3 and the Bulgarian educational software product Envision were mostly used. 


\section{Methodology of the study}

The presented model has been tested in practice in 2014/2015. The study involved $804^{\text {th }}$ grade students, divided into two main groups - experimental group (EG) - Roma students and control group (CG) - Bulgarian students. The CG included 40 students from the Municipality of Yambol, and the EG - 40 students from the Municipality of Veliko Tarnovo.

The reporting of the results is based on preliminary defined criteria and indicators. For the purposes of this study I present some of the results obtained from the data under Criterion I - Ability to recognize and identify facts and events and Indicator: 1 - Able to recognize representatives of ethnic communities by pictures reflecting the cultural specifics in traditional clothing (symbol of culture). The obtained data are ensured by tests for checking students' skills at the entry, intermediate, and exit levels.

The data was analysed statisticaly using the Statgraphics.

\section{Analysis of the results}

The formulations of the presented criterion and indicator are compliant with the level "Remember" in Bloom's taxonomy. This is one of the most widely used taxonomies for educational purposes and for the development of tests to assess students' achievement. In its core is a scale of six main cognitive levels: knowledge, understanding, application, analysis, synthesis, evaluation. In 2001, the taxonomy was revised by Andersen and there were structural and terminological changes introduced. The words used to name the individual levels change from nouns to verbs. This is how the new categories are named: remember, understand, apply, analyze, evaluate, create. For each of the levels, "active verbs" are used to represent a particular participants' action or behavior. The level "Remember" is illustrated by the verbs: remembers, recognizes, recalls (Bogdanov, 2011, p. 10) In accordance with the above criterion and indicator, the achievements of students at the entry, intermediate and exit levels are assessed. The average values of Control Group (CG) and Experimental Group (EG) are monitored. The basis of this analysis is the students' achievements according to the correctly recognized number of paintings and their connection with the name of the ethnic community. The differences are compared statistically by reporting the results for each CG and EG student. 
The comparison of the Control Group (CG) and Experimental Group's (EG)achievements is additionally conducted by analysis of variance for repeated measurements. The results are shown in Table 1.

Table 1. Fisher's criterion and P (F, Df1, Df2) when checking the hypothesis of equality of a series of average values. Task 1.

\begin{tabular}{|l|c|c|c|c|c|}
\hline \multicolumn{1}{|c|}{ Source } & Sum of Squares & Df & Mean Square & F-Ratio & P-Value \\
\hline Between groups & 411.202 & 14 & 29.3715 & $\mathbf{1 7 . 8 4}$ & $\mathbf{0 . 0 0 0 0}$ \\
\hline Within groups & 380.233 & 231 & 1.64603 & & \\
\hline Total (Corr.) & 791.435 & 245 & & & \\
\hline
\end{tabular}

The statistical significance of the studied effects is seen by the value of the observed significance level. If the obtained value of $\mathrm{F}$ is less than the critical value $\left(F<F_{a ; k_{1} ; k}\right)$ or $\mathrm{P}\left(\mathrm{F}, k_{1}, k_{2}\right) \geq \alpha$, it is assumed that the null hypothesis does not contradict the experimental data. Otherwise, the null hypothesis is rejected.

The obtained results and their graphical presentation demonstrate that there is a relatively large difference in the students' answers. This is evident from the presented average values for entry, intermediate and exit levels. The achievements of the CG $4^{\text {th }}$-graders for entry level are oriented towards the higher values and are more condensed, while the EG students' results are expressed in lower values and there is a greater distraction. Therefore, the students in the control classes have higher values of the entry measurement in contrast to the students in the experimental classes. This means that when completing the test task all CG students correctly identified and linked with an arrow four of the five pictures in the test. Therefore, students show good skills of recognizing external cultural features reflected in traditional clothing of the ethnic communities (Armenian, Romani, Jewish, Bulgarian, etc.). The average values of the EG students vary in the range between: $(-1.53)$ and $(-1.42)$. The average values reported in the intermediate measurement are almost the same. A visible change in the average values of the EG and CG students occurs within the exit measurement. The differences between the results at the entry and intermediate levels can be explained as follows - the probable reason for high results of the CG students may be due to an accidental correct answer or the so-called "guessing" the right answer. Because of the analysis of the entry and intermediate levels results, a decision was made to complicate the task. This change was necessary in order to avoid the chance of guessing the correct answer. Thus, in the exit level test, new requirements have been added to the first task. That meant that students 
were required not only to recognize traditional clothing, but also to name elements and/or parts of it in order to demonstrate more in-depth knowledge.

\section{Methodical ideas for the formation of sociocultural competence in the conditions of digitalization}

Figure 1 and 2. The elektronic textbooks - examples

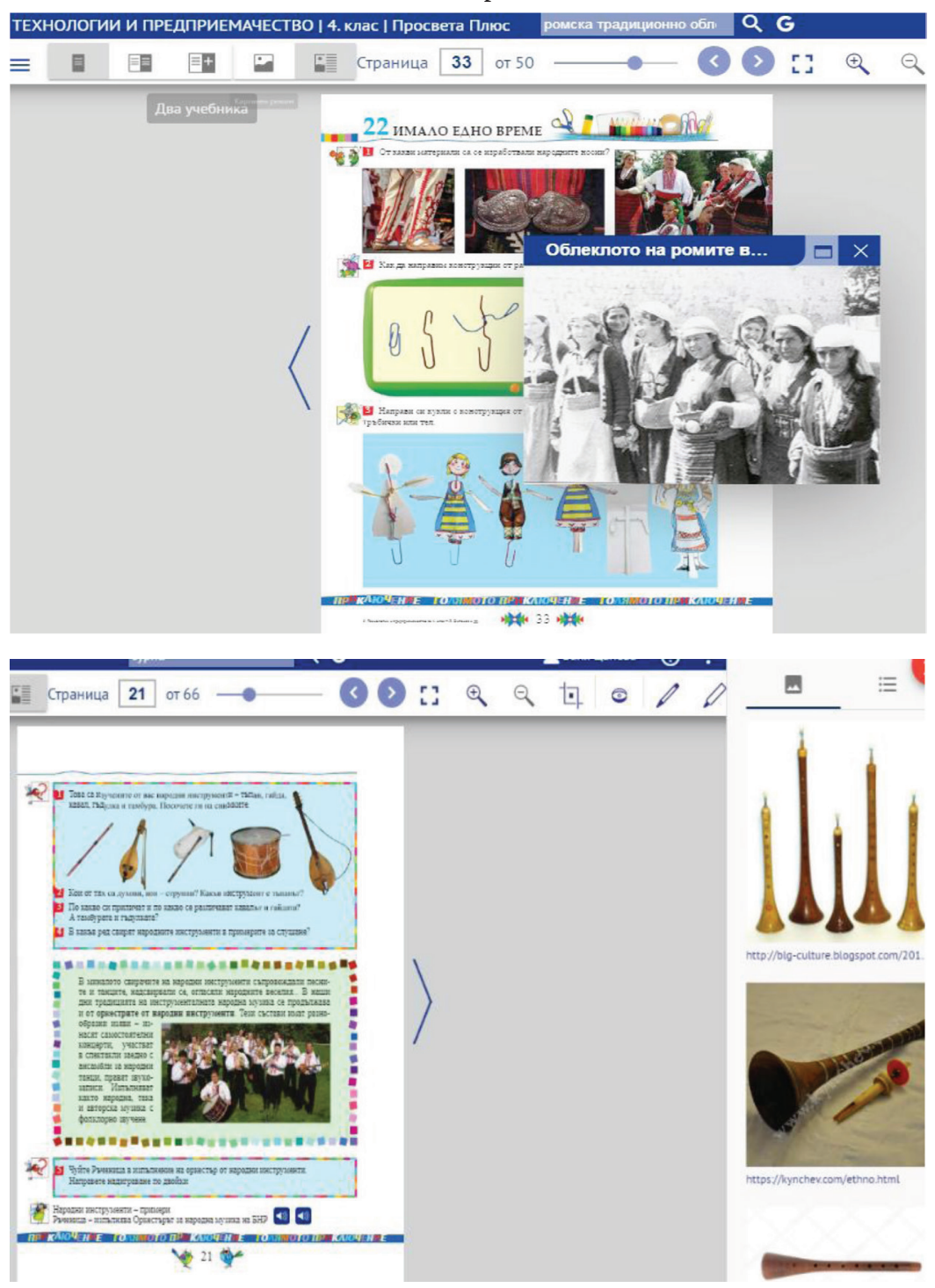


The Bulgarian educational system uses textbooks and workbooks both on paper and electronically. The electronic textbooks have been developed in compliance with the students' age specificities as indicated in Art. 153, paragraph (2) of the PSEA (Act, 2016, p. 54). For the model's purposes, etextbooks have not been used, but their capabilities guarantee a successful achievement of sociocultural competence if they are applied purposefully in the learning process. Electronic textbooks are essentially digital versions of the printed textbooks. They include variety of electronic resources for carrying out a lesson: video files, tests, games, exercises, etc. The e-textbooks and their content allow the formation of sociocultural competence in 7-11 years old students in the way described above in the model. For example, in the $4^{\text {th }}$ Grade Textbook on Technology and Entrepreneurship the topic "Once upon a time" is included. It presupposes acquaintance with cultural traditions and customs in Bulgarian folklore. The theme gives an opportunity to reveal the rich heritage of traditional Bulgarian folklore to be revealed. At the same time, elements from the folklore of other ethnic communities in Bulgaria can be presented and similarities and differences can be highlighted, for example in traditional clothing among Bulgarians and the Roma. To accomplish that, the teacher could present the photo material of traditional Roma clothing included in the textbook. The e-textbook could provide an integrative connection with music as well. Appropriate music files can be found embedded in e-textbooks or through the Internet connection, revealing the richness of traditional folklore for a given culture.

In the Covid-19 pandemic situation, e-textbooks are widely used in online learning for students of all levels. They are extremely useful as they provide a full experience of the content to be learned. They allow not only teaching new material, but also assessing students achievements. Most often this is done through built-in tests and exercises. E-textbooks also provide the possibility of a non-stop educational process during the pandemic. The direct observations as well as the shared opinions support the claim that the effect of e-textbooks usage leads to excellence and continuous learning process despite the different conditions the contemporary realities impose.

\section{Conclusions}

The fact that the Bulgarian society consists of various ethnic groups requires high-level communication skills and sociocultural competence of teachers. The presented model for the formation of sociocultural competence and the 
described methodological ideas for the application of e-textbooks provide additional ways for establishing and maintaining sociocultural relation in 7-11 years old students from different ethnic communities.

The presented model of training for the formation of socio-cultural competence in 7-11 year old students from ethnic communities and the described methodological ideas for the application of e-textbooks confirm the importance of the problem. Achieving socio-cultural competence in primary school is an urgent need to gain a positive, tolerant attitude towards the "different" and the "otherness" from an early age. It is an indisputable fact that in recent years special attention has been paid to the problems of intercultural education, and this implies stimulating the interests of students to study the cultures of different communities in Bulgaria and around the world. The aim is to discover and develop the potential of each student, regardless of their culture and ethnicity.

\section{Bibliography}

Bogdanov, S. 2011. Pedagogicheski iziskvania pri razrabotvane na elektronni didakticheski materiali v obuchenieto po suvremenni ezitsi. Sofia: Nov bulgarski universitet.

Chavdarova-Kostova, S. 2010. Suvremenni predizvikatelstva pred interkulturnoto vuzpitanie. Sofia: Obrazovanie.

Chomsky, N. 1965. Aspects of the theory of syntax. Cambridge, Massachusetts: The M.I.T. Press.

Common European Framework of Reference for Languages. 2001.

Dimitrova, I. 2019. Bulgarskata kartina na sveta v obuchenieto po bulgarski ezik kato vtori chugd ezik. Veliko Turnovo: Universitetsko izdatelstvo: „Sv. sv. Kiril i Metodii".

Dimitrova, D. 2020. Interkulturnata kompetentnost v usloviata na digitalnia svyat. Plovdiv: Astarta.

Dimitrova, D. 2020. Sociokulturnata kompetentnost na uchenicite ot nachalna uchilishtna vuzrast. Teoria i praktika. Plovdiv: Astarta

Hofstede, G., Pidursun, B.P and Hofstede, Y.H. 2003. Izledvane na kulturata. Upragnenia, istorii i sintetichni kulturi. Sofia: Klasika Stil.

Hymes, D. 1973. On communicative competence. In: Pridand, J.B. and Homes, J. eds. Sociolinguistics. Selected readings. Harmondsworth: Penguin, pp. 269-293. 
Molle, K., Ilieva-Baltova, P. and Eftimova, A. 2004. Ezikova i komunikativna kompetentnost. Sofia: Sema RSH

Zakon za preduchilishtnoto i uchilishtnoto obrazovanie. 2015. Obn. Dv., br.79 ot 13 oktomvri 2015. 